\section{EMBRYRIDDLE \\ Aeronautical University}

SCHOLARLY COMMONS

\section{International Journal of Aviation,} Aeronautics, and Aerospace

2-19-2015

\title{
Regional Aviation Early Career Pilot Attributes Study
}

\author{
Stewart Wayne Schreckengast \\ University of South Australia, stewart.schreckengast@unisa.edu.au \\ Douglas A. Drury \\ University of South Australia, doug.drury@unisa.edu.au
}

Follow this and additional works at: https://commons.erau.edu/ijaaa

Part of the Aviation Safety and Security Commons, and the Management and Operations Commons

\section{Scholarly Commons Citation}

Schreckengast, S. W., \& Drury, D. A. (2015). Regional Aviation Early Career Pilot Attributes Study. International Journal of Aviation, Aeronautics, and Aerospace, 2(1). https://doi.org/10.15394/ ijaaa.2015.1049

This Article is brought to you for free and open access by the Journals at Scholarly Commons. It has been accepted for inclusion in International Journal of Aviation, Aeronautics, and Aerospace by an authorized administrator of Scholarly Commons. For more information, please contact commons@erau.edu. 


\section{Regional Aviation Early Career Pilot Attributes Study}

\section{Cover Page Footnote}

The authors appreciate the support of the Regional Aviation Association of Australia and its members for their contributions to this study. 
Traditionally the military or general aviation have been the trainingground for early career regional airline pilots (Mitchell, n.d.a). With the reduction in military pilot training and the high cost of general aviation flying, universities and airlines are undertaking ab-initio training of potential airline pilots. While there are technical standards for specific pilot knowledge, skill and flight performance, there is only guidance material on non-technical skills. Nontechnical skills are defined as:

the mental, social, and personal-management abilities that complement the technical skills of workers and contribute to safe and effective performance in complex work systems. They include competencies such as decision-making, workload management, team communication, situation awareness, and stress management. (CASA, 2011, p. 8)

The use of non-technical behaviour markers to identify a unique set of interpersonal skills for flight crews was identified by the aviation industry as a key factor in improving safety (Flin, Martin, Goeters, Hormann, Amalberti, Valot, $\&$ Nijhuis, 2003). However, most non-technical skills development is done using other programs that are modelled on specific cultures that may or may not define the behaviours that fit within an organisation (Fletcher, Flin, McGeorge, Glavin, Maran, \& Patey, 2003; Engle, 2000).

Currently there is great emphasis on the transition of training and checking from prescriptive milestones to competency based measures. Such a transition is challenging because of the difficulties in establishing clear indicators or criteria to ensure competency. With such challenges, the establishment of competency criteria for non-technical skills is even more daunting. Traditionally, career pilots gained non-technical skills by on-the-job training; essentially they would follow senior pilots to observe and emulate their actions. Such an unstructured process tends to produce a wide variety of results that are not fully compatible with aviation industry needs. The industry identified the need for human factors skills in the early 70's that began the development of Crew Resource Management (CRM) (Cooper, White, \& Lauber, 1979; Helmreich \& Foushee, 1993). The first generation CRM programs were rejected by the pilot group as "psychobabble" and therefore were not taken seriously (Helmreich, Merritt, \& Wilhelm, 1999). Over time the development of CRM evolved to focus on the issues flight crews 
encountered with advanced flight decks and thus became a useful tool in the facilitation of soft or non-technical skills.

The development of advanced avionics has changed the criteria that the aviation industry applies to identify early career pilots (Fanjoy, Young \& Suckow, 2006). Pilots are less task focused and have become system monitors thus changing the dynamics of the skills sets deemed most necessary to function on an automated flight deck (Endsley, 1996). Moreover, as the aviation industry continues to expand and the pool of new entry pilots is reduced, pilot selection and promotion may not continue to allow unstructured non-technical skill training. It is reasonable to believe that Regional Airlines will have to recruit pilots from other countries in light of a limited supply of qualified candidates.

The globalisation of aviation is creating challenges for organisations seeking qualified pilots from within their own national cultures. Expatriate pilots are being enlisted to meet these demands for organisations expanding their presence in the global market. There needs to be a shift in how we develop nontechnical skills programs that must reflect the distinct cultural aspects of these crews, brought together with similar technical qualifications, to create an understanding of the diversity of the multicultural flight deck (Engle, 2000). Based upon the hierarchical nature of the flight deck it is imperative from a safety standpoint that non-technical training development strives to find a program that acknowledges the multicultural values in what Hofstede (2005) defines as Power Distance, the Collective, and the Individualistic differences of national culture. Also, as aircraft and airspace systems evolve, traditional training requirements may no longer meet the competency needs of the industry.

This presents an interesting safety question in that as the demographics and qualifications of culturally diverse candidates' changes does the industry make the assumption that everyone has had the same level of technical and nontechnical training? Should the International Civil Aviation Organization (ICAO) set a minimum hour level and type of experience that is accepted as a global standard? Current changes to the minimum qualifications requirements for new hire pilots in most mature aviation markets makes the journey to the airlines expensive in both time and resources. For most pilots, doing the "hard yards" to build flight time, the opportunities to work for reputable organisations are few and sometimes far between (Fullingim, 2011). Back of the clock freight flying does 
not follow the same regulatory and organisational scrutiny for bush pilot care as can be expected with commercial pilot Regular Public Transport (RPT) operations (Michalski \& Bearman, 2014). The skills that are developed come from nurturing a rough running engine or partial systems failures and are based upon our most basic instinct for survival of the self in the development of judgement, and may be defined as aeronautical decisions making (Jensen, 1989).

As noted in the Introduction, the Australian Civil Aviation Safety Authority (CASA) has developed guidance material regarding non-technical skills. They further discuss that non-technical skills might also be identified as 'human factors' but this might not appropriately align with the overall human factors discipline that is more expansive than non-technical skills. CASA also notes that non-technical skills are not only essential for emergency situations, but are equally important for safe and efficient normal operations and routine work conditions. These attributes or markets are essential in normal operation observations and can be inputs into the Threat and Error Management, Crew Resource Management and Safety Management System programs.

In the study by Todd and Thomas (2013), the significant non-technical skill identified by three airlines included: situational awareness, communication, crew resource management, command, airmanship, briefing, support duties, assertion, conflict resolution, environmental awareness, weather assessment, leadership, handover, traffic awareness and teamwork. Most of these attributes are included in this study or directly relate to the attributes addressed by the airlines. Their study further identified that assertion and situational awareness were key attributes.

Globally, ICAO is one of the leaders in human performance training. ICAO introduced human performance and outlined the needs for human factors and skills training throughout the gambit of the aviation industry (ICAO, 1998). Later it introduced the Multi-crew Pilot License (MPL) to facilitate the development of ab-initio pilots to meet specified aviation needs. Under this new MPL license, airlines and fight training organizations should collaborate to train a new pilot to be type rated in a specific aircraft at the completion of their training. While this has not been fully embraced by many nations, including the United States, industry leaders are aware of this program and there is a need for airlines and universities to form alliances to provide technical as well as non-technical air 
carrier training (Ruiz, 2004). It has further been noted that the crew environment and crew coordination embrace best practices in the aircraft simulators at universities where standardization and competencies can be achieved without the pressures of flight schedules or economic demands (Banard, 2000). Furthermore, the need for scenario-based simulator training has been recommendation in numerous National Transportation Safety Board accident and incident reports.

Thus there may be an opportunity to condense some aspects of aviation training along with redirection of those efforts into non-technical knowledge, skills and human performance. The advantage of such redirection is more effective training. In the Federal Aviation Administration (FAA) Aviation Instructor's Handbook (2008) it is further noted that:

Research indicates that students completing cooperative learning group tasks tend to have higher test scores, higher self-esteem, improved social skills, and greater comprehension of the subjects they are studying. Perhaps the most significant characteristic of group learning is that it continually requires active participation of the student in the learning process (p. 4-20).

A potential secondary benefit is the enhancement of such areas as aeronautical decision making, aviation economics, employee and passenger enjoyment among other yet to be identified opportunities.

\section{Methodology}

This study has received approval through the University of South Australia's Human Research Ethics Committee. A summary of this survey is contained in Appendix 1 of this report. An aviation management survey was developed with the Regional Aviation Association of Australia (RAAA) Training and Education Committee (TEC) and the University of South Australia to sample the desired attributes of early career pilots from a management point of view. This survey was adopted from the CASA 2011 Non-technical Skills Advisory Publication and distributed to TEC members and the University human factors team between April and July 2014. This survey was initially provided to RAAA members via an email and then as a letter reminder during August and September 2014. This report is the findings from that survey. 
The survey results were also discussed at the RAAA Annual Conference in October 2014. During this Conference additional management viewpoints were acquired. Utilizing these management desired attributes as a starting point, a parallel survey will be provided to early career RAAA pilots to identify their perspective of how their university experience prepared them for a career in aviation. The results of that survey are anticipated in early 2015.

\section{Findings}

The RAAA has over 100 corporate members of which about two dozen are passenger and air cargo regional air carriers. This initial survey represents the anonymous and voluntary results of $12(48 \%)$ of the 25 passenger or air cargo regional air carrier members. While the survey does not allow a direct correlation of aviation organizations and management desires for early career pilot attributes, the survey did provide a well distributed input across Australia.

- All the states of Australia were represented as locations of the airline company except Tasmania, with the largest state response coming from Northern Territory and South Australia and the remaining states having either 1 or 2 responses.

- All the states of Australia were represented as sources of early career pilots, with the largest state for pilot source coming from South Australia, Queensland, New South Wales, Victoria and Western Australia.

- Overall the balance of early career (0-5 years), mid-career (5-10 years) and mature career $(10+$ years $)$ pilots was similar, with mature career being the largest group.

Based upon the voluntary and anonymous results of the SurveyMonkey submissions, a summary of Appendix 1 responses for early career pilot attributes have been separated into High, Medium and Low priority through a 5 point Likert scale; however, it is noteworthy that even the lowest priority was desired by most members.

- Highest priority early career attributes valued by aviation managers were (Likert 4.1 to 4.7 ):

- Manual aircraft flight skills

- Regulation and compliance

- Aircraft systems knowledge 
- Physical conditioning and aeromedical

- The medium priority early career attributes valued by aviation managers were (Likert 3.3 to 4.0 ):

- Human factors and fatigue risk management

- Interview and communication skills

- Crew resource management

- Safety Management Systems

- Avionics and automation application

- The lower priority early career attributes valued by aviation managers were (Likert 2.0 to 3.0):

- Multi-crew pilot training

- Airline financial and operating knowledge

- Undergraduate degree

- Graduate degree

The member responses for additional emphasis for pilot training have been separated into High, Medium and Low priority; and again, it is noteworthy that even the lowest priority was still desired by most members.

- Highest priority for additional emphasis for early career pilot training were (Likert 4.1 to 4.8 ):

- Manual aircraft flight skills

- Aircraft systems knowledge

- Avionics and Automation application

- Regulation and compliance

- Human factors and fatigue risk management

- Crew resource management

- The medium priority for additional emphasis for early career pilot training were (Likert 3.8 to 4.0 ):

- Aerodynamics regarding specific aircraft

- Future aspirations and command ability

- Interview and communication skills

- English language proficiency

- Safety Management Systems and Safety Culture

- Simulator and abnormal conditions competencies

- The lower priority for additional emphasis for early career training were (Likert 2.9 to 3.7 ): 
- Physical conditioning and aeromedical

- Specific examples of aircraft or personal events in life

- Multi-crew pilot training

- Airline business and commercial operating knowledge

- Transition from military to commercial operations

- Transition from regional to long-haul operations

The additional desired attributes expressed by aviation managers of early career pilots were mostly focused around motivation, passenger interface, communication skills, and the ability for lateral thinking.

These additional attributes are somewhat in parallel with the manager's recommendations of additional educational emphasis for early career pilot training such as practical application of theory, pilotage without the use of automation, and passenger and cargo handling services.

There was also much discussion both during the survey and at the RAAA Conference about the quality of flight instructors, their maturity to provide appropriate insight into commercial aviation operations, and their preoccupation with simply building flight hours. Many expressed the need for greater involvement by CASA and the aviation community to harmonize and enhance the resources made available to flight instructors in order to keep pace with the changing aviation marketplace and varied cultural developments in the industry. This is especially important for abbreviated courses such as MPL which focus on technical mastery of cockpit activities without sufficient opportunities for social and cultural development related to non-technical skills.

\section{Discussion}

There is a wealth of research and commentary regarding the benefits of formal university aviation programs vs traditional flight instruction technical training. There are also numerous examples of highly successful aviation pilots and managers without a university degree. In compromise, the Federal Aviation Administration and other civil aviation authorities have given significant experience allowances to pilots who have graduated from formal aviation programs. In order to assist government, industry and educators in providing the best value for money in their regulatory, operational and training programs, a structures survey into the viewpoints of management and early career pilots may 
provide a better understanding of these issues and build a foundation for enhancing the development of future pilots.

In a similar concern, Gary Kiteley, the former executive director of the University Aviation Association in the United States noted that there are over 120 colleges and universities in the United States with about half offering aviation maintenance programs. Such non-flying aviation programs would have a similar need for non-technical skills (Mitchell, n.d.b). It should also be noted that when airlines recruit an early carrier pilot - "They are rarely, if ever, looking for someone with a basic qualification who can do nothing more than fill the first officer's seat." (PROPILOT, 2014).

\section{Conclusions}

In general, these initial results place significant early career pilot attributes on basic flying skills along with a solid understanding of regulations and aircraft systems. Much less significance was placed on non-technical skills. In fact, a university degree, and especially a graduate university degree had the lowest priority. These attributes directly correlate to the recommendations for greater emphasis in pilot training.

With that in mind, the free comment section was almost entirely related to non-technical skills such as employee motivation, employee-customer interface, situational awareness and lateral thinking. Such soft-skills are certainly not in the average flight training organizations. However, university aviation degree programs should be developed to provide both the technical skills and the people skills required for regional aviation environment (Mitchell, n.d.a). As noted by George (2012, p.65) only about $10 \%$ of the aviation industry is in the air while about $90 \%$ of the industry is on the ground. Thus due consideration needs to be provided for non-technical skill training in aviation maintenance, aviation management and other related aviation programs.

\section{Recommendations}

1. As the development and implementation of the new CASR Part 141 and 142 evolve, the RAAA must participate and ensure that CASA is aware of the aviation industry desires for early career commercial pilots and that 
programs are in place to ensure that flight instruction and non-technical skills are aligned with these industry needs.

2. RAAA and aviation training organizations must develop and implement such non-technical skills training to meet industry needs. The RAAA TEC should be the focal point of these initiatives.

3. The RAAA and universities should collaborate to conduct follow-on support for early career pilot training, should continue to sample the progress of such implementation and ensure that these programs are aligned with CASA regulatory development.

4. The RAAA and aviation maintenance training organizations undertake a collaborative initiative to evaluate the need for non-technical skill training for these personnel.

5. RAAA TEC to conduct complementary follow-on early career survey for pilot's viewpoint. 


\section{References}

Banard, K. (2000 April). Ascent to flight training. Tech Directions, 59(9), 26.

Cooper, G., White, M., \& Lauber, J. (1979). Proceedings of the NASA workshop on resource management training for airline flight crews (CP-2120).

Moffett Field, CA: National Aeronautics and Space Administration, Ames Research Center.

Civil Aviation Safety Authority (CASA). (2011). Non-Technical Skills Training and Assessment for Regular Public Transport Operations. Civil Aviation Advisory Publication CAAP SMS-3(1). Canberra, Australia. Retrieved from http://www.casa.gov.au/wcmswr/_assets/main/ download/caaps/ops/sms-3-1.pdf

Endsley, M. (1996). Automation and situation awareness. In R. Parasuraman, \& M. Mouloua (Eds), Automation and human performance: Theory and applications (pp. 163-181). Mahwah, NJ: Erlbaum.

Engle, M. (2000). Culture in the cockpit-CRM in a multicultural world. Journal of Air Transportation World-Wide, 5(1), 107-14.

Fanjoy, R., Young, J., \& Suckow, M. (2006). The experience factor: A regional airline view of pilot candidates qualifications. Collegiate Aviation Review, 24(1), 67-72.

Federal Aviation Administration (FAA). (2008). Aviation Instructor's Handbook. FAA-H-8083-9A. Washington, DC: Author. Retrieved from http://www.faa.gov/regulations_policies/handbooks_manuals/aviation/ aviation_instructors_handbook/media/faa-h-8083-9a.pdf

Fletcher, G., Flin, R., McGeorge, P., Glavin, R., Maran, N., \& Patey, R. (2003). Anaesthetists' non-technical skills (ANTS): Evaluation of a behavioural marker system. British Journal of Anaesthesia, 90(5), 580-588. doi: $10.1093 /$ bja/aeg112

Flin, R. Martin, L., Goeters, M., Hörmann, J., Amalberti, R., Valot, C., \& Nijhuis, H. (2003). Development of the NOTECHS (non-technical skills) system for assessing pilots' CRM skills. Human Factors and Aerospace Safety 3(2), 95-117. Surrey, UK: Ashgate Publishing. 
Fullingim, J. (2011). The marketability of higher education aviation graduates as perceived by regional airline pilots. Collegiate Aviation Review, 29(1), $28-44$.

George, K. (2012). That used to be us: Through the eyes of the aviation industry. Collegiate Aviation Review 30(1), 62-76.

Helmreich, R. \& Foushee, H. (1993). Why Crew Resource Management?

Empirical and theoretical bases of human factors training in aviation. In E. Wiener, B. Kanki, \& R. Helmreich (Eds.), Cockpit Resource Management (pp. 3-45). San Diego, CA: Academic Press.

doi: $10.1177 / 106480469300100315$

Helmreich, R., Merritt, A., \& Wilhelm, J. (1999). The evolution of Crew Resource Management in commercial aviation. International Journal of Aviation Psychology, 9, 19-32. doi:10.1207/s15327108ijap0901_2

Hofstede, G. \& Hofstede, G. J. (2005). Cultures and organizations: Software of the mind. Intercultural cooperation and its importance for survival $\left(2^{\text {nd }}\right.$ ed.). New York: McGraw-Hill.

International Civil Aviation Organization (ICAO). (1998). Human factors training manual, Doc 9683-AN/950. Montreal, Canada: Author.

Jensen, R. (1989). Aeronautical decision making - Cockpit resource management (DOT/FAA/PM-86/46). Arlington, VA: Systems Control Technology.

Retrieved from http://handle.dtic.mil/100.2/ADA205115

Michalski, D. \& Bearman, C. (2014). Factors affecting the decision making of pilots who fly in outback Australia. Safety Science, 68, 288-293.

doi: 10.1016/j.ssci.2014.03.005

Mitchell, F. (n.d.a). A bridge to the future. University Aviation Association member archive. University Aviation Association member archive. Retrieved from www.uaa.aero.

Mitchell, F. (n.d.b). Clipping the Aviation Industry's Wings: The growing manpower shortage. University Aviation Association member archive. Retrieved from www.uaa.aero. 
PROPILOT. (2014). What airlines are looking for. Retrieved from http://www.propilot.eu/your-career-in-aviation/ what-airlines-are-looking-for/

Ruiz, J. (2004). The perceived value of airline flight operations internship activities and/or benefits in the pursuit of career goals. Collegiate Aviation Review, 22(1). 71-82.

Todd, M. \& Thomas, M. (2013). Pilot experience and performance in an airline environment. Australian Transport Safety Bureau. Canberra. Australia. Retrieved from http://www.atsb.gov.au/media/4171790/ ar-2012-023_final.pdf 


\section{Appendix 1}

\section{RAAA member response demography Q3 and Q4, 2014.}

Which state(s) are your company conducting business?

$\begin{array}{ll}\text { South Australia } & -3 \\ \text { Queensland } & -2 \\ \text { New South Wales } & -1 \\ \text { Northern Territory } & -3 \\ \text { Victoria } & -1 \\ \text { Western Australia } & -2 \\ \text { Tasmania } & -0 \\ \text { International } & -0\end{array}$

Which state(s) are your new hire pilots most likely to receive their flight training?

$\begin{array}{ll}\text { South Australia } & -4 \\ \text { Queensland } & -4 \\ \text { New South Wales } & -4 \\ \text { Northern Territory } & -3 \\ \text { Victoria } & -4 \\ \text { Western Australia } & -5 \\ \text { Tasmania } & -1 \\ \text { International } & -2\end{array}$

What is the level of experience of your pilots:

Early career (0-5 years) - $32 \%$ of the airline pilots were early career Mid-career (5-10 years) - $26 \%$ of the airline pilots were mid-career Mature career $(10+$ years $)-42 \%$ of the airline pilots were mature career

\section{Attributes of new hire pilots}

What are the most important attributes for your company for selection of a new hire pilot, with less than 5 years flying experience?

- Aircraft systems knowledge

$$
-4.3 \text { of } 5
$$

- Airline financial and operating knowledge - 3.0

- Avionics and automation application - 3.3

- Crew resource management - 3.8

- Human factors and fatigue risk management - 4.0

- Interview and communication skills $\quad-4.0$

- Manual aircraft flight skills $\quad-\mathbf{4 . 7}$ 
- Multi-crew pilot training $\quad-2.8$

- Physical conditioning and aeromedical $\quad-4.1$

- Regulation and compliance $\quad \mathbf{- 4 . 6}$

- Safety Management Systems $\quad-3.7$

- Undergraduate degree $\quad-2.2$

- Graduate degree $\quad-2.0$

The following open comments were provided to the first series of attributes:

- Teamwork x 3

- Motivation and dedication to work hard x 3

- Need for lateral thinking x 2

- Communication skills x 2

- Common sense

- Customer service

- Positive attitude and appropriate dress and actions

- Not too greedy for salary

- Realistic attitude towards general aviation

Select the 5 attributes that should receive greater emphasis in professional pilot training:

- Aerodynamics regarding specific aircraft $\quad-3.8$ of 5

- Aircraft systems knowledge $\quad \mathbf{- 4 . 3}$

- Airline business and commercial operating knowledge $\quad-3.1$

- Avionics and Automation application - 4.2

- Crew resource management $\quad-4.1$

- English language proficiency - 3.9

- Future aspirations and command ability - 3.9

- Human factors and fatigue risk management $\quad-4.1$

- Interview and communication skills -4.0

- Manual aircraft flight skills $\quad-4.8$

- Multi-crew pilot training - 3.5

- Physical conditioning and aeromedical - 3.7

- Regulation and compliance - 4.1

- Safety Management Systems and Safety Culture - 4.0

- Simulator and abnormal conditions competencies $\quad-4.0$

- Specific examples of aircraft or personal events in life $\quad-3.7$

- Transition from military to commercial operations -3.3

- Transition from regional to long-haul operations - 2.9 
The following open comments were provided to the need for greater emphasis questions:

- Flight Management

- Communication skills x 2

- Practical application of theory

- Basic visual navigation with the aid of GPS

- Passenger and cargo handling and service

- Keeping the aircraft clean and ready

- Situational awareness x 3

- $\quad$ TEM and CRM x 2

What other areas to you feel are important in the professional development of new hire pilots?

- Retention of required knowledge skills - don't just memorize for testing and then forget.

- CASA review of flight instructor qualifications - if instructors do not have industry experience or understand the skills necessary to succeed in the industry then they can't pass these on to their students.

- Need to instil the importance for flight instructors to look beyond building flight time, and making an investment into the aviation industry. 